\title{
The Use of Mathematical Statistics Methods in Modelling the Psychophysiological «Value» of Cognitive Activity of Students with Different Levels of Academic Success
}

\author{
Iryna Kalynychenko, Hanna Zaikina, Hanna Latina, \\ Olha Skyba, Dmytro Kalynychenko
}

\author{
Sumy State Pedagogical University named after A. S. Makarenko, 87 Romenska Str., Sumy, Ukraine
}

\begin{abstract}
Mathematical interpretation of the psychophysiological «value» of modern schoolchildren' cognitive activity will allow to identify risk groups, especially among students with high and average academic achievement.

The results allowed to establish dependence of the type of functions and properties, at the expense of which the "value» of the students' activity was manifested, from the way of organizing the educational process.

The article argues that regression models of psychophysiological «value» have different filling of variables depending on gender, intensity of information and physical loads.

The variables that are most often included in psychophysiological «value» regression models, i.e., are the most important markers of change in the «price» of activity of students with high academic achievement, include thinking flexibility level, extraversion, anxiety level, speed of complex visualmotor reaction, as well as average length of cardiocycles during mental activity.
\end{abstract}

DOI: 10.18421/TEM103-41

https://doi.org/10.18421/TEM103-41

Corresponding author: Olha Skyba,

Sumy State Pedagogical University named after A. S. Makarenko, 87 Romenska Str., Sumy, Ukraine.

Email: skybaolha@gmail.com

Received: 27 February 2021.

Revised: 01 August 2021.

Accepted: 07 August 2021.

Published: 27 August 2021.

(c) BY-NC-ND (C) 2021 Olha Skyba et al; published by UIKTEN. This work is licensed under the Creative Commons Attribution-NonCommercial-NoDerivs 4.0 License.

The article is published with Open Access at www.temjournal.com
Keywords - mathematical model, regression equation, cognitive status, heart rate variability, functional state, neuroticism, visual-motor reactions

\section{Introduction}

Today, the issue of schoolchildren's psychophysiological state assessment, determining trends to exhausting reserves and organism systems under the influence of information loads, which are increasing every year due to intensification of the educational process in general secondary education institutions still remains relevant [1]. Taking into account the negative dynamics of changes in the psychophysiological and functional states of modern schoolchildren, it is urgent to develop and substantiate a methodological approach to the construction of mathematical models of the psychophysiological «value» of cognitive activity of students with different academic achievements depending on the level of information load and physical activity [2], [3].

The issues of modern schoolchildren's academic achievement and the factors which influence it, including intensity of physical and information load, levels of cognitive processes development, measure of organism regulatory systems tension during cognitive activity, etc., continue to be studied by scientists all over the world and have not lost their relevance [4], [5].

The scientists established connections between physical fitness, behaviour, health status affecting certain brain tissues and neural processes, and academic achievement [6], [7], between children's motor and cognitive skills [8], [9], between daily physical activity and children's performing function [3], [10]. The role of individual cognitive properties, especially attention and different types of thinking, in the development of cognitive activity in general and school maturity has been studied [11], [12], [13]. 
In addition, the connection between physical activity and cognitive development [14] and the role of the emotional component [15] in early childhood have been studied. It should be noted that the problem of academic underachievement of modern schoolchildren has been studied as a social problem [16], as well as the impact of the occupational health of secondary school teachers on the success of students' educational and cognitive activity [1].

Therefore, relevant remains the issue of the method of determining and mathematical calculation of the psychophysiological «value» of cognitive activity, taking into account the laws of indicators correlation that have been minimized by stepwise regression (excluding those indicators that are not crucial), as well as the possibility of quantitative representation of generalized features which represent the complex of elements of the cognitive activity »value».

The purpose of the study was to develop mathematical models of the psychophysiological «value» of cognitive activity of students with high academic achievement by means of regression analysis.

The experiment envisaged establishing a relationship between the components of the psychophysiological «value» and the intensity of information and physical loads.

\section{Materials and Methods}

Variables of «value» mathematical models were determined by correlation and factor analyzes of the indicators of students' functional state and cognitive properties [17].

Students' personal qualities and the functional state of their body were assessed by the levels of neuroticism, extraversion-introversion, manifestation of borderline neurotic disorders, well-being, activity, mood, as well as the dynamics of changes in mental performance during the working day and week [18], [19], [20].

All these functions were evaluated according to well-known psychological blank methods, which were selected on the principles of informativeness, adequacy, validity, reliability, accessibility, as well as the possibility of conducting experiment in the conditions of a comprehensive education institution without disrupting the educational process.

To evaluate the functional state of the cardiovascular system and the body as a whole during the mental activity and in the state of rest, the method of variational heart rate monitoring was used. Heart rate variability (HRV) assessment was performed using the software and device Cardiospektr («Solvaig», Kyiv).

In the course of the study, the neurodynamic properties were evaluated by the latent period (LP) parameters of the simple visual-motor reaction (SVMR), the choice reaction of one out of three stimuli (CR 1-3), the choice reaction of two out of three stimuli (CR 2-3) [21]. The neurodynamic properties of students' HNA have been studied using the «Diagnost-1» computer system [21].

Changes in the mental capacity (MC) of schoolchildren in the dynamics of the working day and week were determined using a two-minute correction test by the letter tables of V. Anfimov according to the method of M. Antropova and V. Kozlova [22], which allowed to obtain a comprehensive assessment of the individual values of the obtained mental performance indicators. The result of tasks accomplishment was considered as an indicator of the activity of the second signal system. By the number of errors was determined the degree of students' fatigue, which allowed us to speak about the violation of the balance of excitatory and inhibitory processes.

The study was conducted on the basis of Sumy secondary schools of I-III grades. It involved 109 students of secondary schools with high academic achievement (10-12 - average grade point) aged 11-15 years, differing in the intensity of educational and physical load. High school students with excess of the regulated hygienic norm of educational load by $18,2 \%$ and 2 hours of physical education per week made up the main group of the study (MG). Students of a specialized secondary education institution that had additional lessons of physical education in the schedule -5 lessons per week (at the expence of reducing the amount of weekly information load) were assigned to the comparison group № $1\left(\mathrm{CG}_{1}\right)$ and students of the institution of general secondary education with the traditional form of organization of educational process and 3 physical education classes per week were included in the comparison group № $2\left(\mathrm{CG}_{2}\right)$.

\section{Results}

Regression models were created taking into account variables that underwent correlation and factor analysis. Based on the selected indicators, the model parameters were calculated for each group, depending on the school and gender. For the boys of the MG with high academic achievement (AA), the regression model parameters are presented in Table 1. 
Table 1. PPV regression model parameters for boys of the $M G$ with high AA

\begin{tabular}{|l|c|c|c|c|c|c|c|}
\hline \multicolumn{1}{|c|}{ Variables } & $\beta$ & $\mathrm{S}_{\beta}$ & $\mathrm{a}$ & $\mathrm{S}_{\mathrm{a}}$ & $\mathrm{t}_{\mathrm{a}}$ & $p_{\mathrm{a}}$ & Share of contribution, \% \\
\hline Free variable $\left(\mathrm{a}_{0}\right)$ & & & 11,41 & 0,82 & 13,96 & $\mathbf{0 , 0 0 0 0}$ & \\
\hline Concept thinking & 0,42 & 0,12 & 0,24 & 0,07 & 3,56 & $\mathbf{0 , 0 0 1}$ & 32,42 \\
\hline Depression & $-0,52$ & 0,12 & $-0,11$ & 0,02 & $-4,38$ & $\mathbf{0 , 0 0 0 1}$ & 48,77 \\
\hline LP CR 2-3 & $-0,32$ & 0,12 & $-0,003$ & 0,001 & $-2,73$ & $\mathbf{0 , 0 1}$ & 18,81 \\
\hline
\end{tabular}

As it can be seen from the table, all factors have a significant effect on function $(\mathrm{p}<0,05)$. Overall, the model is also reliable and adequate $(\mathrm{F}=15,12$; $\mathrm{p}<0,0001)$. The largest contribution to the PPV makes the depression rate, as indicated by the beta coefficient (-0.52), which is $48,77 \%$ of the contribution share of this factor. Therefore, the equation of the PPV regression model with the coefficients for boys with high AA will be as follows:

$$
y=11,41+0,24 x_{1}-0,11 x_{2}-0,003 x_{3}
$$

where: $\mathrm{y}-\mathrm{PPV} ; \mathrm{x}_{1}-$ level of conceptual thinking development (points); $\mathrm{x}_{2}$-depression (points); $\mathrm{x}_{3}-$ LP CR 2-3 (ms).

For the boys with high $\mathrm{AA}$ of the $\mathrm{CG}_{1}$, the regression model parameters based on the selected factors are presented in Table 2.

As it can be seen from the table, only one factor has a probable effect on the function $(p<0,05)$. That is, the PPV model of this group of students can be only one-factor, only under such conditions it is reliable and adequate $(F=7,66 ; \mathrm{p}<0,05)$.

Table 2. PPV regression model parameters for boys of the $C_{1}$ with high AA

\begin{tabular}{|l|c|c|c|c|c|c|c|}
\hline \multicolumn{1}{|c|}{ Variables } & $\beta$ & $\mathrm{S}_{\beta}$ & $\mathrm{a}$ & $\mathrm{S}_{\mathrm{a}}$ & $\mathrm{t}_{\mathrm{a}}$ & $p_{\mathrm{a}}$ & $\begin{array}{c}\text { Share of } \\
\text { contribution, } \%\end{array}$ \\
\hline Free variable $\left(\mathrm{a}_{0}\right)$ & & & 9,56 & 0,20 & 47,55 & $\mathbf{0 , 0 0 0}$ & \\
\hline LF fon rest & $-0,81$ & 0,29 & $-0,00007$ & 0,00003 & $-2,77$ & $\mathbf{0 , 0 5}$ & 100 \\
\hline
\end{tabular}

Therefore, the equation of the PPV factor regression model with respect to the coefficient and free variable for the boys of the $\mathrm{CG}_{1}$ with high academic achievement will be as follows:

$$
y=9,56-0,00007 x
$$

where: $\mathrm{y}$ - PPV; $\mathrm{x}$ - an indicator of the lowfrequency component of the HRV spectrum (ms).

The parameters of the PPV regression model for the boys of the $\mathrm{CG}_{2}$ with high academic achievement are presented in Table 3.
As it can be seen from the table, only one factor that reflects the magnitude of the latent period of the complex visual-motor reaction $(p>0,05)$ has no influence on the function. All other factors have a probable effect $(p<0,05)$. Taking into account that the model as a whole is adequate and reliable $(F=13,93 \mathrm{p}<0,01)$, all indicators can be used as components of this model.

Table 3. PPV regression model parameters for boys of the $\mathrm{CG}_{2}$ with high $\mathrm{AA}$

\begin{tabular}{|l|c|c|c|c|c|c|c|}
\hline \multicolumn{1}{|c|}{ Variables } & $\beta$ & $\mathrm{S}_{\beta}$ & $\mathrm{a}$ & $\mathrm{Sa}$ & $\mathrm{t}_{\mathrm{a}}$ & $p_{\mathrm{a}}$ & $\begin{array}{c}\text { Share of } \\
\text { contribution, \% }\end{array}$ \\
\hline Free variable $\left(\mathrm{a}_{0}\right)$ & & & 6,10 & 0,56 & 10,86 & $\mathbf{0 , 0 0 0}$ & \\
\hline Flexibility of thinking & 0,42 & 0,14 & 0,16 & 0,05 & 2,98 & $\mathbf{0 , 0 2 0}$ & 8,83 \\
\hline Extraversion & 0,78 & 0,20 & 0,14 & 0,04 & 3,87 & $\mathbf{0 , 0 0 6}$ & 30,78 \\
\hline Anxiety & 0,91 & 0,18 & 0,14 & 0,03 & 5,01 & $\mathbf{0 , 0 0 1}$ & 41,43 \\
\hline LP CR 1-3 & 0,22 & 0,13 & 0,002 & 0,001 & 1,69 & 0,13 & 2,34 \\
\hline VLF fon activity & $-0,57$ & 0,22 & $-0,0001$ & 0,00004 & $-2,66$ & $\mathbf{0 , 0 3}$ & 16,60 \\
\hline
\end{tabular}

Therefore, the equation of the PPV regression model with the coefficients for the boys of the $\mathrm{CG}_{2}$ with high AA will be as follows:

$y=6,10+0,16 x_{1}+0,14 x_{2}+0,14 x_{3}+0,002 x_{4}-0,0001 x_{5}$

where: $\mathrm{y}-\mathrm{PPV} ; \mathrm{x}_{1}-$ an indicator of the level of thinking flexibility development (points); $\mathrm{x}_{2}-$ extraversion rate (points); $\mathrm{x}_{3}$ - anxiety level (points); $\mathrm{x}_{4}-$ magnitude of the latent period of complex visual-motor reaction (CR 1-3) (ms); $\mathrm{x}_{5}-$ the power index of the very low frequency spectrum of VLF (VLF fon) during mental activity ( $\mathrm{ms}^{2}$ ).

The parameters of the PPV regression model for the girls of the MG with high AA are presented in Table 4. 
As it can be seen from the table, all selected factors $(p<0,05)$ have a probable influence on the magnitude of the function. Overall, the model is adequate and reliable $(F=8,87 \mathrm{p}<0,0001)$.

Table 4. PPV regression model parameters for girls of the $M G$ with high AA

\begin{tabular}{|l|c|c|c|c|c|c|c|}
\hline \multicolumn{1}{|c|}{ Variables } & $\beta$ & $\mathrm{S}_{\beta}$ & $\mathrm{a}$ & $\mathrm{Sa}$ & $\mathrm{t}_{\mathrm{a}}$ & $p_{\mathrm{a}}$ & $\begin{array}{c}\text { Share of } \\
\text { contribution, } \%\end{array}$ \\
\hline Free variable $\left(\mathrm{a}_{0}\right)$ & & & 9,34 & 0,63 & 14,80 & $\mathbf{0 , 0 0 0}$ & \\
\hline Flexibility of thinking & 0,34 & 0,11 & 0,15 & 0,05 & 3,15 & $\mathbf{0 , 0 0 2}$ & 33,19 \\
\hline LP CR 1-3 & 0,32 & 0,10 & 0,003 & 0,001 & 3,08 & $\mathbf{0 , 0 0 3}$ & 30,19 \\
\hline Mood & $-0,27$ & 0,11 & $-0,03$ & 0,01 & $-2,53$ & $\mathbf{0 , 0 1}$ & 20,97 \\
\hline HF fon activity & $-0,23$ & 0,11 & $-0,00001$ & 0,00001 & $-2,18$ & $\mathbf{0 , 0 3}$ & 15,64 \\
\hline
\end{tabular}

The equation of the PPV regression model taking into account the coefficients for the girls with high AA will have the following form:

$$
y=9,34+0,15 x_{1}+0,003 x_{2}-0,03 x_{3}-0,0001 x_{4}
$$

where: $\mathrm{y}-\mathrm{PPV} ; \mathrm{x}_{1}$ - an indicator of the level of thinking flexibility development (points); $\mathrm{x}_{2}-$ the magnitude of the latent period of complex visualmotor reaction (LP CR 1-3) (ms); $\mathrm{x}_{3}-\operatorname{mood}$ indicator (points); $\mathrm{x}_{4}$ - wave power indicator of $\mathrm{HRV}$ high frequency spectrum in the state of mental activity $\left(\mathrm{ms}^{2}\right)$.
The parameters of the PPV regression model for the girls of the $\mathrm{CG}_{1}$ with high $\mathrm{AA}$ are presented in Table 5 .

As it can be seen from the table, the properties of thinking and the mid-week mental performance indicator have a probable impact on manifestation of the PPV activity of girls of the $\mathrm{CG}_{1}$ with high AA $(\mathrm{p}<0,05)$. Considering that, overall, this model is adequate and reliable $-F=7,49 \mathrm{p}<0,01$, all factors can be involved. The largest contribution to the PPV criterion makes the indicator of thinking flexibility development (the share of contribution is $47,31 \%$ ).

Table 5. PPV regression model parameters for girls of the $C_{1}$ with high AA

\begin{tabular}{|l|c|c|c|c|c|c|c|}
\hline \multicolumn{1}{|c|}{ Variables } & $\beta$ & $\mathrm{S}_{\beta}$ & $\mathrm{a}$ & $\mathrm{Sa}$ & $\mathrm{t}_{\mathrm{a}}$ & $p_{\mathrm{a}}$ & $\begin{array}{c}\text { Share of } \\
\text { contribution, \% }\end{array}$ \\
\hline Free variable $\left(\mathrm{a}_{0}\right)$ & & & 10,72 & 0,67 & 15,96 & $\mathbf{0 , 0 0 0}$ & \\
\hline Q mid-week & $-0,54$ & 0,21 & $-0,03$ & 0,01 & $-2,58$ & $\mathbf{0 , 0 4}$ & 31,73 \\
\hline Flexibility of thinking & 0,66 & 0,19 & 0,20 & 0,06 & 3,43 & $\mathbf{0 , 0 1}$ & 47,31 \\
\hline Extraversion & $-0,34$ & 0,18 & $-0,03$ & 0,02 & $-1,92$ & 0,09 & 12,80 \\
\hline NN fon activity & $-0,27$ & 0,18 & $-0,001$ & 0,001 & $-1,50$ & 0,18 & 8,15 \\
\hline
\end{tabular}

The equation of the PPV regression model with the coefficients for the girls of the $\mathrm{CG}_{1}$ with high AA will have the following form:

$$
y=10,72-0,03 x_{1}+0,20 x_{2}-0,03 x_{3}-0,001 x_{4}
$$

where: $\mathrm{y}-\mathrm{PPV} ; \mathrm{x}_{1}$ - mid-week mental performance (conditional units); $\mathrm{x}_{2}-$ the level of thinking flexibility development (points); $\mathrm{x}_{3}-$ extraversion level (points); $\mathrm{x}_{4}$ - the value inversely proportional to the heart rate, determined in the state of mental activity ( $\mathrm{NN}$ fon) (ms).
The parameters of the PPV regression model for the girls of the $\mathrm{CG}_{2}$ with high AA are presented in Table 6.

As it can be seen from the table, only the level of visual-figurative thinking development has no probable impact on the formation of PPV of students of this category. But taking into account the fact that the model as a whole is reliable and adequate $(F=5.94 p<0.01)$, all indicators can be used to construct a PPV regression model. The largest contribution to the PPV has an average duration of cardiac intervals $(\mathrm{NN})$, which is $51.95 \%$.

Table 6. PPV regression model parameters for girls of the $\mathrm{CG}_{2}$ with high AA

\begin{tabular}{|l|c|c|c|c|c|c|c|}
\hline \multicolumn{1}{|c|}{ Variables } & $\beta$ & $\mathrm{S}_{\beta}$ & $\mathrm{a}$ & $\mathrm{Sa}$ & $\mathrm{t}_{\mathrm{a}}$ & $p_{\mathrm{a}}$ & $\begin{array}{c}\text { Share of } \\
\text { contribution, \% }\end{array}$ \\
\hline Free variable $\left(\mathrm{a}_{0}\right.$ ) & & & 8,64 & 0,47 & 18,38 & $\mathbf{0 , 0 0 0}$ & \\
\hline Visual-figurative thinking & 0,22 & 0,13 & 0,09 & 0,06 & 1,66 & 0,10 & 20,54 \\
\hline Anxiety & $-0,26$ & 0,13 & $-0,03$ & 0,02 & $-1,95$ & $\mathbf{0 , 0 6}$ & 27,50 \\
\hline NN fon activity & 0,35 & 0,13 & 0,002 & 0,001 & 2,63 & $\mathbf{0 , 0 1}$ & 51,95 \\
\hline
\end{tabular}


The equation of the PPV regression model, taking into account coefficients for the girls of the $\mathrm{GP}_{2}$ with high AA will be as follows:

$$
y=8,64+0,09 x_{1}-0,03 x_{2}-0,002 x_{3}
$$

where: $\mathrm{y}-\mathrm{PPV} ; \mathrm{x}_{1}$ - the level of visual-figurative thinking development (points); $x_{2}-$ the anxiety level (points); $\mathrm{x}_{3}-$ an indicator of $\mathrm{NN}$ fon in a state of mental activity (ms).
In order to establish the relationship between academic achievement and the composition of variables of the «value» regression models, there is a need to build such mathematical models for students with average levels of academic achievement.

The parameters of the regression model of PPV for the boys of the MG with average AA are presented in Table 7.

Table 7. PPV regression model parameters for boys of the $M G$ with average AA

\begin{tabular}{|c|c|c|c|c|c|c|c|}
\hline Variables & $\beta$ & $\mathrm{S}_{\beta}$ & $\mathrm{a}$ & $\mathrm{Sa}$ & $\mathrm{t}_{\mathrm{a}}$ & $p_{\mathrm{a}}$ & $\begin{array}{c}\text { Share of } \\
\text { contribution, } \%\end{array}$ \\
\hline Free variable $\left(\mathrm{a}_{0}\right)$ & & & 4,86 & 0,34 & 14,33 & $\mathbf{0 , 0 0 0}$ & \\
\hline Q Saturday & 0,32 & 0,23 & 0,02 & 0,01 & 1,42 & 0,21 & 15,2 \\
\hline Flexibility of thinking & 0,65 & 0,19 & 0,25 & 0,07 & 3,38 & $\mathbf{0 , 0 2}$ & 61,22 \\
\hline LF fon rest & 0,40 & 0,23 & 0,0001 & 0,004 & 1,76 & 0,14 & 23,57 \\
\hline
\end{tabular}

As it can be seen from the table, the probable influence on the PPV in the boys with average AA has only an indicator of flexibility of thinking $(p<0,05)$, but the model is generally adequate and reliable $(F=8,05 ; \mathrm{p}<0,05)$. Therefore, the equation of the PPV regression model, taking into account the coefficients for the boys of the MG with average AA will be as follows:

$y=4,86+0,02 x_{1}+0,25 x_{2}+0,0001 x_{3}$

Table 8. PPV regression model parameters for boys of the $C_{1}$ with average AA

\begin{tabular}{|l|c|c|c|c|c|c|c|}
\hline \multicolumn{1}{|c|}{ Variables } & $\beta$ & $\mathrm{S}_{\beta}$ & $\mathrm{a}$ & $\mathrm{Sa}$ & $\mathrm{t}_{\mathrm{a}}$ & $p_{\mathrm{a}}$ & $\begin{array}{c}\text { Share of } \\
\text { contribution, \% }\end{array}$ \\
\hline Free variable $\left(\mathrm{a}_{0}\right)$ & & & 6,62 & 0,47 & 14,05 & $\mathbf{0 , 0 0 0}$ & \\
\hline Q Saturday & $-0,26$ & 0,12 & $-0,04$ & 0,02 & $-2,25$ & $\mathbf{0 , 0 2 8}$ & 61,86 \\
\hline Neuroticism & $-0,21$ & 0,12 & $-0,05$ & 0,03 & $-1,76$ & 0,08 & 38,14 \\
\hline
\end{tabular}

As it can be seen from the table, the probable influence on the PPV in the boys of the $\mathrm{CG}_{1}$ with average AA has an indicator of mental capacity at the end of the week $(p<0,05)$, but the model is generally adequate and reliable $(F=4,44 ; \mathrm{p}<0,05)$. Therefore, the equation of the PPV regression model, taking into account the coefficients for the boys of the $\mathrm{CG}_{1}$ with average AA will be as follows: where: $\mathrm{y}-\mathrm{PPV} ; \mathrm{x}_{1}-$ mental capacity at the end of the week $\left(\mathrm{Q}_{\mathrm{sat}}\right)$ (points); $\mathrm{x}_{2}$ - the level of development of the flexibility of thinking (points); $\mathrm{x}_{3}$ - low-frequency power of the HRV spectrum at rest $\left(\mathrm{ms}^{2}\right)$.

The parameters of the PPV regression model for the boys of the $\mathrm{CG}_{1}$ with average AA are presented in Table 8.

Table 9. PPV regression model parameters for boys of the $C_{2}$ with average $A A$

\begin{tabular}{|l|c|c|c|c|c|c|c|}
\hline \multicolumn{1}{|c|}{ Variables } & $\beta$ & $\mathrm{S}_{\beta}$ & $\mathrm{a}$ & $\mathrm{Sa}$ & $\mathrm{t}_{\mathrm{a}}$ & $p_{\mathrm{a}}$ & $\begin{array}{c}\text { Share of } \\
\text { contribution, } \%\end{array}$ \\
\hline Free variable $\left(\mathrm{a}_{0}\right)$ & & & 8,01 & 0,76 & 10,52 & $\mathbf{0 , 0 0 0}$ & \\
\hline Visual-figurative thinking & $-0,49$ & 0,19 & $-0,21$ & 0,08 & $-2,64$ & $\mathbf{0 , 0 1}$ & 66,12 \\
\hline LP SVMR & $-0,35$ & 0,19 & $-0,004$ & 0,002 & $-1,89$ & $\mathbf{0 , 0 5}$ & 33,87 \\
\hline
\end{tabular}

As it can be seen from the table, all factors have a probable influence on the PPV in the boys of the $\mathrm{CG}_{2}$ with average AA $(p<0,05)$. The model is generally adequate and reliable $(F=4,28 ; \mathrm{p}<0,05)$. Therefore,

$$
y=6,62-0,04 x_{1}-0,05 x_{2}
$$

where: $\mathrm{y}-\mathrm{PPV} ; \mathrm{x}_{1}-$ mental capacity at the end of the week (points); $x_{2}-$ level of neuroticism (points).

The parameters of the PPV regression model for the boys of the $\mathrm{CG}_{2}$ with average AA are presented in Table 9. the equation of the PPV regression model, taking into account the coefficients for the boys of the $\mathrm{CG}_{2}$ with average AA will be as follows: 
$y=8,01-0,21 x_{1}-0,004 x_{2}$

where: $\mathrm{y}-\mathrm{PPV} ; \mathrm{x}_{1}-$ level of visual-figurative thinking development (points); $\mathrm{x}_{2}-$ speed of simple visual-motor reaction (LP SVMR) (ms).
The parameters of the PPV regression model for the girls of the $\mathrm{CG}_{1}$ with average AA are presented in Table 10.

Table 10. PPV regression model parameters for girls of the $C_{1}$ with average $A A$

\begin{tabular}{|l|c|c|c|c|c|c|c|}
\hline \multicolumn{1}{|c|}{ Variables } & $\beta$ & $\mathrm{S}_{\beta}$ & $\mathrm{a}$ & $\mathrm{Sa}$ & $\mathrm{t}_{\mathrm{a}}$ & $p_{\mathrm{a}}$ & $\begin{array}{c}\text { Share of } \\
\text { contribution, \% }\end{array}$ \\
\hline Free variable $\left(\mathrm{a}_{0}\right)$ & & & 4,34 & 0,20 & 21,69 & $\mathbf{0 , 0 0 0}$ & \\
\hline Q mid-week & $-0,16$ & 0,06 & $-0,008$ & 0,002 & $-2,68$ & $\mathbf{0 , 0 5}$ & 0,12 \\
\hline Mood & $-0,54$ & 0,03 & $-0,04$ & 0,002 & $-17,44$ & $\mathbf{0 , 0 0 0}$ & 1,41 \\
\hline Depression & $-3,00$ & 0,17 & $-0,53$ & 0,03 & $-17,49$ & $\mathbf{0 , 0 0 0}$ & 43,65 \\
\hline Asthenia & 2,78 & 0,16 & 0,50 & 0,03 & 17,19 & $\mathbf{0 , 0 0 0}$ & 37,45 \\
\hline Vegetative disorders & 0,74 & 0,09 & 0,09 & 0,01 & 8,29 & $\mathbf{0 , 0 0 3}$ & 2,69 \\
\hline LP SVMR & 0,77 & 0,05 & 0,01 & 0,001 & 14,50 & $\mathbf{0 , 0 0 0}$ & 2,89 \\
\hline LF fon rest & $-1,21$ & 0,08 & $-0,0001$ & 0,001 & $-14,66$ & $\mathbf{0 , 0 0 0}$ & 7,11 \\
\hline Baevsky index (activity) & $-0,32$ & 0,03 & $-0,003$ & 0,001 & $-8,97$ & $\mathbf{0 , 0 0 2}$ & 0,48 \\
\hline VLF fon activity & 0,93 & 0,05 & 0,0003 & 0,001 & 18,38 & $\mathbf{0 , 0 0 0}$ & 4,19 \\
\hline
\end{tabular}

As it can be seen from the table, all selected indicators have a probable influence on the PPV in the girls of the $\mathrm{CG}_{1}$ with average AA $(p<0,05)$, in addition, the model is generally adequate and reliable
$(F=177,90 ; \mathrm{p}<0,001)$. Therefore, the equation of the PPV regression model, taking into account the coefficients for the girls of the $\mathrm{CG}_{1}$ with average AA will be as follows:

$$
y=4,34-0,008 x_{1}-0,04 x_{2}-0,53 x_{3}+0,50 x_{4}+0,09 x_{5}+0,01 x_{6}-0,0001 x_{7}-0,003 x_{8}+0,0003 x_{9}
$$

where: $\mathrm{y}-\mathrm{PPV} ; \mathrm{x}_{1}-$ mental capacity in the middle of the week (points); $x_{2}-$ mood (points); $x_{3}$ - depression (points); $\mathrm{x}_{4}-$ asthenia (points); $\mathrm{x}_{5}-$ vegetative disorders (points); $\mathrm{x}_{6}-$ latent period of simple visualmotor reaction (ms); $\mathrm{x}_{7}-$ low-frequency power of the HRV spectrum $\left(\mathrm{ms}^{2}\right) ; \mathrm{x}_{8}-$ Baevsky index in the state of mental activity (points); $x_{9}-$ power of the waves of the very low-frequency HRV spectrum in the state of mental activity.

The parameters of the PPV regression model for the girls of the $\mathrm{CG}_{2}$ with average $\mathrm{AA}$ are presented in Table 11.

Table 11. PPV regression model parameters for girls of the $C_{2}$ with average $A A$

\begin{tabular}{|l|c|c|c|c|c|c|c|}
\hline \multicolumn{1}{|c|}{ Variables } & $\beta$ & $\mathrm{S}_{\beta}$ & $\mathrm{a}$ & $\mathrm{Sa}$ & $\mathrm{t}_{\mathrm{a}}$ & $p_{\mathrm{a}}$ & $\begin{array}{c}\text { Share of } \\
\text { contribution, \% }\end{array}$ \\
\hline Free variable $\left(\mathrm{a}_{0}\right)$ & & & 6,68 & 0,16 & 42,27 & $\mathbf{0 , 0 0 0}$ & \\
\hline Q Monday & $-0,44$ & 0,16 & $-0,02$ & 0,009 & $-2,62$ & $\mathbf{0 , 0 4 7}$ & 16,78 \\
\hline Q mid-week & 0,28 & 0,17 & 0,01 & 0,01 & 1,64 & 0,16 & 6,88 \\
\hline Vegetative disorders & 0,23 & 0,11 & 0,02 & 0,01 & 2,17 & $\mathbf{0 , 0 5}$ & 4,67 \\
\hline VLF fon rest & $-0,90$ & 0,11 & $-0,0001$ & 0,0001 & $-8,35$ & $\mathbf{0 , 0 0 0}$ & 71,66 \\
\hline
\end{tabular}

As it can be seen from the table, all selected indicators have a probable influence on the PPV in the girls of the $\mathrm{CG}_{2}$ with average AA $(\mathrm{p}<0,05)$, except for mental capacity in the middle of the week, but the model is generally adequate and reliable $(F=34,79 ; \mathrm{p}<0,01)$. Therefore, the equation of the PPV regression model, taking into account the coefficients for the girls of the $\mathrm{CG}_{2}$ with average AA will be as follows:

$y=6,68-0,02 x_{1}+0,01 x_{2}+0,02 x_{3}-0,0001 x_{4}(11)$ where: $\mathrm{y}-\mathrm{PPV} ; \mathrm{x}_{1}-$ mental capacity at the beginning of the week (points); $\mathrm{x}_{2}$-mental capacity in the middle of the week (points); $\mathrm{x}_{3}$ - vegetative disorders (points); $\mathrm{x}_{4}-$ power of the waves of the very low-frequency HRV spectrum in the state of rest.

Among the girls of the MG, the average level of the academic achievement was not found.

The next step was to create a regression model taking into account the variables that passed through factor analysis without division into groups according to academic achievement, intensity of physical and information activity. Based on the selected indicators, the parameters of the model were calculated the values of which are presented in Table 12. In general, the proposed model is reliable and adequate $(\mathrm{F}=42,26 ; \mathrm{p}<0,0001)$. 
As it can be seen from the table, mental capacity at the beginning of the week ( $\left.\mathrm{Q}_{\text {Mon }}\right)$, as well as changes in the mean lengths of successive RR intervals at rest $\left(\mathrm{NN}_{\mathrm{FON}}\right.$ rest) and during mental activity $\left(\mathrm{NN}_{\mathrm{FON}}\right.$ activity) tend to affect the psychophysiological «value» $\left(p_{\mathrm{a}}>0,05\right)$, while the influence of other indicators on the «value» as a whole was significant $\left(p_{\mathrm{a}}<0,001\right)$. The only exception is the indicator of mental capacity in the middle of the week $\left(\mathrm{Q}_{\text {mid-week }}\right)$, the probability of which is $0,04\left(p_{\mathrm{a}}<0,05\right)$. But given that the model as a whole is reliable and adequate, all variables can be left to build a multifactor linear model.

Table 12. Parameters of the regression model of the psychophysiological «value» of students' cognitive activity

\begin{tabular}{|l|c|c|c|c|c|c|c|}
\hline \multicolumn{1}{|c|}{ Variables } & $\beta$ & $\mathrm{S}_{\beta}$ & $\mathrm{a}$ & $\mathrm{S}_{\mathrm{a}}$ & $\mathrm{t}_{\mathrm{a}}$ & $p_{\mathrm{a}}$ & $\begin{array}{c}\text { Share of } \\
\text { contribution }\end{array}$ \\
\hline Free variable $\left(\mathrm{a}_{0}\right)$ & & & $\mathbf{2 , 2 5 8}$ & 0,27 & 8,37 & $\mathbf{0 , 0 0}$ & \\
\hline $\mathrm{Q}_{\text {Mon }}$ & $-0,02$ & 0,05 & $\mathbf{- 0 , 0 0 1}$ & 0,00 & $-0,34$ & 0,73 & 0,031 \\
\hline $\mathrm{Q}_{\text {mid-week }}$ & $-0,10$ & 0,05 & $\mathbf{- 0 , 0 0 9}$ & 0,01 & $-2,07$ & $\mathbf{0 , 0 4}$ & 1,123 \\
\hline $\mathrm{Q}_{\text {Sat }}$ & $-0,16$ & 0,05 & $\mathbf{- 0 , 0 1 4}$ & 0,00 & $-3,24$ & $\mathbf{0 , 0 0}$ & 2,833 \\
\hline Neuroticism & 0,31 & 0,05 & $\mathbf{0 , 0 4 4}$ & 0,01 & 6,81 & $\mathbf{0 , 0 0}$ & 10,306 \\
\hline Depression & 0,35 & 0,05 & $\mathbf{0 , 0 5 9}$ & 0,01 & 7,44 & $\mathbf{0 , 0 0}$ & 12,847 \\
\hline NN $_{\text {FON }}$ rest & $-0,04$ & 0,07 & $\mathbf{0 , 0 0 0 2}$ & 0,00 & $-0,52$ & 0,60 & 0,156 \\
\hline BI rest & $-0,54$ & 0,05 & $\mathbf{- 0 , 0 0 4}$ & 0,00 & $-10,65$ & $\mathbf{0 , 0 0}$ & 31,474 \\
\hline NN $_{\text {FON }}$ activity & 0,04 & 0,07 & $\mathbf{0 , 0 0 0 2}$ & 0,00 & 0,51 & 0,61 & 0,140 \\
\hline BI activity & 0,62 & 0,05 & $\mathbf{0 , 0 0 3}$ & 0,00 & 11,82 & $\mathbf{0 , 0 0}$ & 41,090 \\
\hline & & & & & & & 100,000 \\
\hline
\end{tabular}

The greatest influence is exerted by the indicators of CVS tension (BI rest, BI activity), and the ratios of beta coefficients show that the influence of BI in the state of activity is 1,15 times greater than in the state of rest $(0,62 / 0,54)$. Also, the influence of these variables is almost 2 times higher than the influence of depression and neuroticism $(\beta=0,35$ and $\beta=0,31)$.

Thus, the equation of the PPV regression model taking into account the coefficients will be as follows:

$$
y=2,258-0,001 x_{1}-0,009 x_{2}-0,014 x_{3}+0,044 x_{4}+0,059 x_{5}+0,0002 x_{6}-0,004 x_{7}+0,0002 x_{8}+0,003 x_{9}
$$

where: $\mathrm{y}-\mathrm{PPV} ; \mathrm{x}_{1}-\mathrm{Q}_{\text {Mon }} ; \mathrm{x}_{2}-\mathrm{Q}_{\text {mid-week }} ; \mathrm{x}_{3}-\mathrm{Q}_{\text {Sat }} ; \mathrm{x}_{4}$ - neuroticism; $\mathrm{x}_{5}-$ depression; $\mathrm{x}_{6}-\mathrm{NN}_{\mathrm{FON}}$ rest; $\mathrm{x}_{7}-$ $\mathrm{BI}$ rest; $\mathrm{x}_{8}-\mathrm{NN}_{\mathrm{FON}}$ activity; $\mathrm{x}_{9}-\mathrm{BI}$ activity.

Given that variables of the same order cannot be used for the regression equation, the indicators that meet this criterion should be presented as an average value, or as a ratio, as it was done during the factor analysis. Then the parameters of the regression model of the psychophysiological «value» of students' cognitive activity will have the values presented in Table 13.

Table 13. Parameters of the regression model of the psychophysiological «value» of students' cognitive activity

\begin{tabular}{|l|c|c|c|c|c|c|c|}
\hline \multicolumn{1}{|c|}{ Variables } & $\beta$ & $\mathrm{S}_{\beta}$ & $\mathrm{a}$ & $\mathrm{Sa}$ & $\mathrm{t}_{\mathrm{a}}$ & $p_{\mathrm{a}}$ & $\begin{array}{c}\text { Share of } \\
\text { contribution }\end{array}$ \\
\hline Neuroticism & $\mathbf{0 , 2 8 5}$ & 0,032 & $\mathbf{0 , 0 6 7}$ & 0,008 & 8,861 & 0,000 & $\mathbf{1 6 , 8 6 6}$ \\
\hline Depression & $\mathbf{0 , 1 6 6}$ & 0,028 & $\mathbf{0 , 0 5 8}$ & 0,010 & 6,043 & 0,000 & $\mathbf{5 , 7 6 0}$ \\
\hline $\mathrm{Q}_{\text {mid-week }}$ & $\mathbf{- 0 , 1 1 6}$ & 0,040 & $\mathbf{- 0 , 0 1 9}$ & 0,006 & $-2,903$ & 0,004 & $\mathbf{2 , 7 9 6}$ \\
\hline $\mathrm{BI}_{\text {rel }}$ & $\mathbf{0 , 5 7 4}$ & 0,058 & $\mathbf{1 , 6 6 3}$ & 0,169 & 9,827 & 0,000 & $\mathbf{6 8 , 6 5 0}$ \\
\hline $\mathrm{NN}_{\text {rel }}$ & $\mathbf{0 , 1 6 9}$ & 0,014 & $\mathbf{0 , 1 4 4}$ & 0,012 & 12,025 & 0,000 & $\mathbf{5 , 9 2 8}$ \\
\hline & & & & & & & 100,000 \\
\hline
\end{tabular}

This model is generally reliable and adequate $(F=1432,6 ; p<0,0001)$. Given that all variables are independent and also have a certain weight (there cannot be a value of 0 ), the regression equation can be constructed without a free variable. Therefore, taking into account all the above mentioned criteria, the PPV regression model of students' cognitive activity will look like this:

$$
\mathrm{PPV}=\log \left(0,067 x_{1}+0,058 x_{2}-0,019 \frac{x_{3}+x_{4}+x_{5}}{3}+1,663 \frac{x_{6}}{x_{7}}+0,144 \frac{x_{8}}{x_{9}}\right)
$$


where: $\mathrm{x}_{1}-$ neuroticism; $\mathrm{x}_{2}-$ depression; $\mathrm{x}_{3}-\mathrm{Q}_{\text {Mon; }}$; $\mathrm{x}_{4}-\mathrm{Q}_{\text {mid-week }} ; \mathrm{x}_{5}-\mathrm{Q}_{\text {Sat }} ; \mathrm{x}_{6}-\mathrm{BI}$ activity; $\mathrm{x}_{7}-\mathrm{BI}$ rest; $\mathrm{x}_{8}$ $-\mathrm{NN}_{\mathrm{FON}}$ activity; $\mathrm{x}_{9}-\mathrm{NN}_{\mathrm{FON}}$ rest.

All the obtained indicators, which are part of the integrated indicator of the PPV, were processed according to both obtained mathematical models, followed by determination of the tension value during the cognitive activity of each individual student according to the established algorithm (Table 14.).

Logarithmization of both models allowed to limit the number of PPV levels and reduce their range.

Table 14. Estimation of psychophysiological «value» of cognitive activity

\begin{tabular}{|c|c|c|}
\hline Number of points for PPV & PPV level & Qualitative assessment of PPV \\
\hline$<1$ & I & Low \\
\hline$\geq 1$, but $<2$ & II & Medium \\
\hline$\geq 2$, but $\leq 3$ & III & High \\
\hline$>3$ & IV & Very high \\
\hline
\end{tabular}

After applying this technique, the number of levels and their ranges for both PPV models were within the same limits. This allowed to create a single variant for determining the PPV level of each student, regardless of the chosen mathematical model.

PPV gradation was performed using the sigma distribution method. The calculation of the PPV indicators was performed by logarithmizing the initial distribution of the PPV, which was abnormal (Fig. 1.), and after this mathematical operation became normal logarithmically.

Thus, II level corresponds to the average value $\bar{x}$, I level: $\bar{x}-\sigma$; III level: $\bar{x}+\sigma$; IV level: $\bar{x}+2 \sigma$.

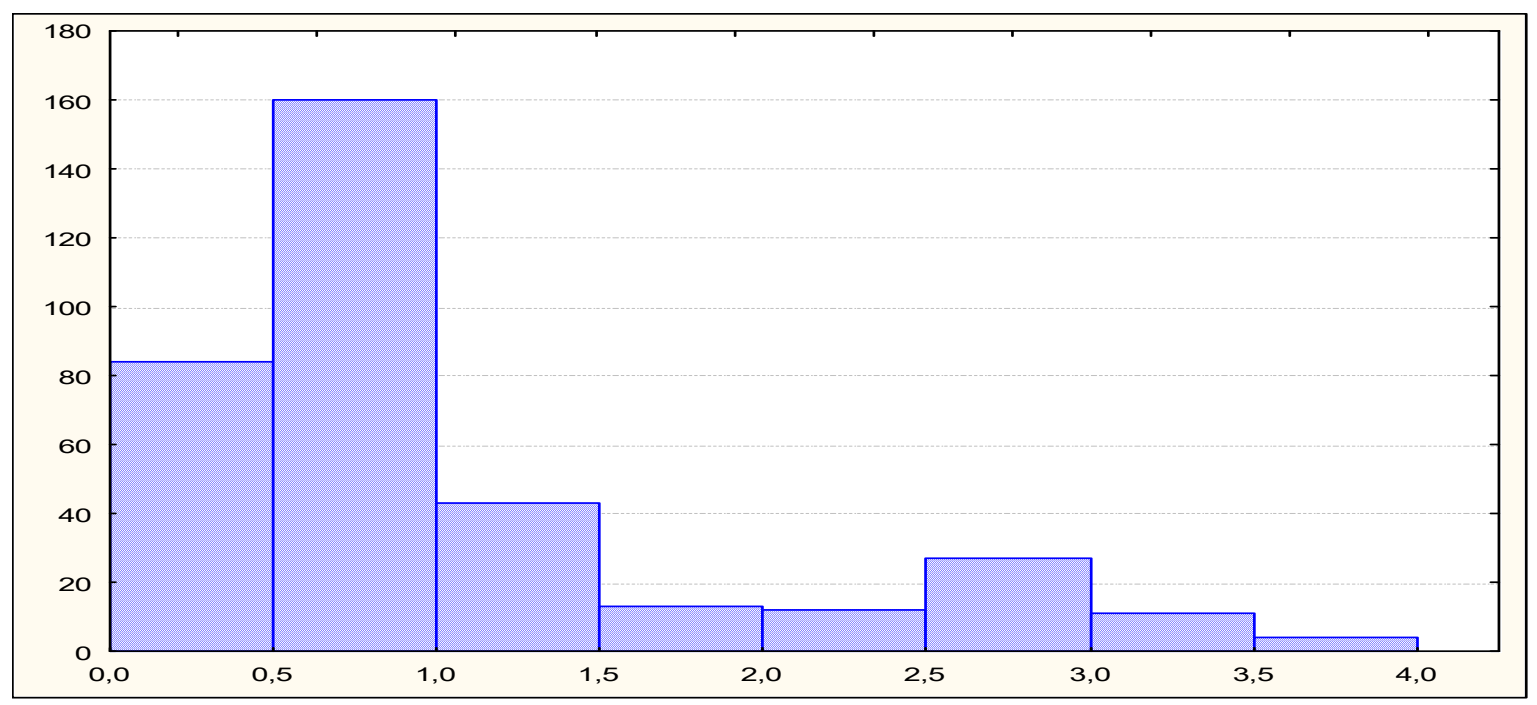

Figure 1. Histogram of the distribution of PPV indicators of schoolchildren of general secondary education institutions of different types

Characteristics of the levels of psychophysiological «value» of mental tension:

I - low level of the PPV mental load of the student - is characterized by the insignificant tension of the main regulatory systems of an organism during mental loading and during weekly educational activity that testifies, on the one hand, to high adaptive possibilities of the student's organism to intensive mental loadings - in case when effectiveness of training and the quality of work performed are assessed as "excellent" or "good"; on the other hand - the lack of activity of the student's motivational and volitional sphere or low mental potential (which must be taken into account when characterizing the PPV of each student), which in turn affects the quality of learning.
II - medium level of PPV mental load of the student - is characterized by the presence of tension in the nervous and cardiovascular systems, but it does not lead to mental fatigue and depletion of major regulatory systems, it is considered as a harmonious ratio of mental intensity and psychophysiological capabilities of the student provided sufficient and high learning efficiency.

III - high level - indicates a low level of adaptive potential of the ogranism to mental loading, reduced functional and psychophysiological state of the student, presence of neurotic disorders, decreased overall body tone, which in turn is a criterion for rehabilitation, recovery measures aimed at elimination and prevention of further mental fatigue, 
taking into account the individual characteristics of each student.

IV - very high level - indicates presence of acute disorders or disruptions of the body's adaptive mechanisms, in addition, may indicate presence of pathological changes, which requires additional examinations of the student and analysis of his/her health status.

\section{Discussion}

Given the fact that there is no analogues of mathematical models of psychophysiological «value» of activity, including cognitive, educational, and mental, it is impossible to compare regression models with the models of other scientists. But it can be compared with the research of psychophysiologists and physiologists who study different activities.

It should be noted that today there are no clearly defined concepts that would explain how the CNS ensures the universality of the thinking process, which plays an important role in mental, cognitive activity of the individual. But there are empirical studies that are devoted to the invetigation of this problem. In our research, we relied on two independent approaches.

The first one is based on the registration of physiological indicators during mental activity, which aims to identify the dynamics of physiological indicators in the process of solving tasks of various types. By changing the types and complexity of tasks, analyzing the concomitant changes in physiological indicators during the study, physiological correlates of performance were obtained and reflected in the regression models of the «value» of activity mathematically. On this basis, the conclusions of other researchers on the features of physiological support for solving tasks of different types are based in [23], [24], [25]. The second approach is based on the fact that the inherent ways of human cognitive activity are reflected in physiological parameters and as a result acquire stable individual characteristics [26], [27].

Previous researchers who studied mental performance and cognitive activity in relation to the manifestations of the activity of the vegetative nervous system [28], have shown that the efficiency and the level of resistance to errors are inversely correlated with the data of the spectral characteristics of the cardiorhythm. Our studies coincide with these results and confirm the fact that the characteristics of heart rate variability reflect the degree of tension during mental activity and affect its effectiveness, thetherfore the indicators of obtained characteristics are one of the variables of proposed regression models of the psychophysiological «value».
As it has been noted above, one of the variables of the regression models is spectral characteristics of heart rate variability - VLF, LF, HF, with a negative sign, indicating a decrease in the level of «value» with increasing power of these spectral ranges. That is, higher quality of mental activity and less tension in persons with high total power and the power of the specified spectral ranges are accompanied by high lability of vegetative indicators, their specificity to the nature of activity as evidenced by previous researchers [12].

In addition, the analysis of the work of previous scientists confirms the gender differences in the vegetative regulation of successful mental activity according to heart rate variability [15], [30], [29] which actually present the PPV regression models for boys and girls.

\section{Conclusions}

Thus, regression models of the psychophysiological «value» have different variables depending on gender, intensity of information and physical loads. Also, within the course of the research it has been established that the filling with variables of the regression model of the psychophysiological «value» of students' educational and cognitive activity depends on academic achievement.

The variables that are most often included in the PPV regression models, i.e., are the most important markers of change in the "value» of activity of students with high academic achievement, include thinking flexibility level, extraversion, anxiety level, speed of complex visual-motor reaction, as well as average length of cardiocycles during mental activity. While the variables that are most often included in the regression models of PPV activities of students with average levels of academic achievement include: mental capacity during the week, the latent period of simple visual-motor reaction, spectral indicators reflecting the activity of the sympathetic HRV, indicators of the levels of manifestation of vegetative disorders, etc.

Processing of the results of psychophysiological examination of students with different levels of information, physical activity and academic achievement by mathematical statistics methods allowed to derive a model of psychophysiological «value» of educational and cognitive activities of modern students, which can be used in general secondary education to prevent mental fatigue and exhaustion. 


\section{References}

[1]. Braun, S. S., Roeser, R. W., Mashburn, A. J., \& Skinner, E. (2019). Middle school teachers' mindfulness, occupational health and well-being, and the quality of teacher-student interactions. Mindfulness, $10(2), 245-255$. https://doi.org/10.1007/s12671-018-0968-2

[2]. Zelazo, P. D. (2015). Executive function: Reflection, iterative reprocessing, complexity, and the developing brain. Developmental Review, 38, 55-68. https://doi.org/10.1016/j.dr.2015.07.001.

[3]. Zelazo, P. D., Forston, J. L., Masten, A. S., \& Carlson, S. M. (2018). Mindfulness plus reflection training: Effects on executive function in early childhood. Frontiers in psychology, 9, 208.

[4]. van der Niet, A. G., Smith, J., Scherder, E. J., Oosterlaan, J., Hartman, E., \& Visscher, C. (2015). Associations between daily physical activity and executive functioning in primary school-aged children. Journal of Science and Medicine in Sport, 18(6), 673-677. doi: 10.1016/j.jsams.2014.09.006.

[5]. Drollette, E. S., Scudder, M. R., Raine, L. B., Moore, R. D., Saliba, B. J., Pontifex, M. B., \& Hillman, C. H. (2014). Acute exercise facilitates brain function and cognition in children who need it most: an ERP study of individual differences in inhibitory control capacity. Developmental cognitive neuroscience, 7, 53-64.

[6]. De Franchis, V., Usai, M. C., Viterbori, P., \& Traverso, L. (2017). Preschool executive functioning and literacy achievement in Grades 1 and 3 of primary school: A longitudinal study. Learning and Individual Differences, 54, 184-195.

doi: 10.1016/j.lindif.2017.01.026

[7]. Hillman, C. H., \& Schott, N. (2013). Der Zusammenhang von Fitness, kognitiver Leistungsfähigkeit und Gehirnzustand im Schulkindalter: Konsequenzen für die schulische Leistungsfähigkeit. Zeitschrift für Sportpsychologie, 20(1), 33-41.

[8]. Alesi, M., Bianco, A., Padulo, J., Vella, F. P., Petrucci, M., Paoli, A., ... \& Pepi, A. (2014). Motor and cognitive development: the role of karate. Muscles, Ligaments and Tendons Journal, 4(2), 114-120. doi: $10.11138 / \mathrm{mltj} / 2014.4 .2 .114$.

[9]. Jäger, K., Schmidt, M., Conzelmann, A., \& Roebers, C. M. (2014). Cognitive and physiological effects of an acute physical activity intervention in elementary school children. Frontiers in psychology, 5, 1473.

[10]. Vernon-Feagans, L., Willoughby, M., \& GarrettPeters, P. (2016). Predictors of Behavioral Regulation in Kindergarten: Household Chaos, Parenting and Early Executive Functions. Dev Psychol, 52(3), 430441. https://doi.org/10.1037/dev0000087.

[11]. Blair, C., \& Raver, C. C. (2015). School readiness and self-regulation: A developmental psychobiological approach. Annual review of psychology, 66, 711-731.
[12]. Carson, V., Hunter, S., Kuzik, N., Wiebe, S. A., Spence, J. C., Friedman, A., ... \& Hinkley, T. (2016). Systematic review of physical activity and cognitive development in early childhood. Journal of science and medicine in sport, 19(7), 573-578.

doi: 10.1016/j.jsams.2015.07.011.

[13]. Mullane, J. C., Lawrence, M. A., Corkum, P. V., Klein, R. M., \& McLaughlin, E. N. (2016). The development of and interaction among alerting, orienting, and executive attention in children. Child Neuropsychology, 22(2), 155-176. doi: 10.1080/09297049.2014.981252

[14]. Constantinidis, C., \& Klingberg, T. (2016). The neuroscience of working memory capacity and training. Nature Reviews Neuroscience, 17(7), 438449. https://doi.org/10.1038/nrn.2016.43

[15]. Nakamichi, K. (2017). Differences in young children's peer preference by inhibitory control and emotion regulation. Psychological reports, 120(5), 805-823. doi: 10.1177/0033294117709260

[16]. Merrill, K. L., Smith, S. W., Cumming, M. M., \& Daunic, A. P. (2017). A review of social problemsolving interventions: Past findings, current status, and future directions. Review of Educational Research, 87(1), 71-102. doi: $10.3102 / 0034654316652943$

[17]. Antomonov, M. Y. Matematicheskaya obrabotka I analiz mediko-biologicheskikh dannykh (Mathematical processing and analysis of biomedical data). 2-e izd. Kyiv: Medinform. 2018; 579. Russian.

[18]. Doskin, V.A., Lavrent'ev, N. A., \& Strongina, O. M. (1975). Psihologicheskij test «SAN» primenitel'no k issledovaniyam v oblasti fiziologii truda. Gigiena truda i professional'nye zabolevaniya, 5, 28-32.

[19]. Karelin, A. (2005). Bol'shaya enciklopediya psihologicheskih testov. Eksmo, Moscow.

[20]. Korol'chuk, M. (2003) Psy`xofiziologiya diyal’nosti: Pidruchny`k dlya studentiv vy`shhy`x navchal'ny`x zakladiv. El’ga, Nika-Centr, Kyiv.

[21]. Makarenko, M. V. (2006). Osnovi profesiynogo vidboru viyskovikh spetsialistiv ta metodiki vivchennya individualnikh psikhofiziologichnikh vidminnostey mizh lyudmi. K.: In-t fiziologii imeni $O$. Bogomoltsya NAN Ukraïni.

[22]. Antropova, M.V. \& Kozlova, V.I. (1984). Methodological recommendations for physiologicalhygienic study of the educational load of learners. APN SSSR, Moscow.

[23]. Kunimasa, S., Miyagi, K., Shimoda, H., \& Ishii, H. (2013, July). A detection method of temporary rest state while performing mental works by measuring physiological indices. In International Conference on Engineering Psychology and Cognitive Ergonomics (pp. 142-150). Springer, Berlin, Heidelberg.

[24]. Siegle, G. J., D'Andrea, W., Jones, N., Hallquist, M. N., Stepp, S. D., Fortunato, A., ... \& Pilkonis, P. A. (2015). Prolonged physiological reactivity and loss: Association of pupillary reactivity with negative thinking and feelings. International Journal of Psychophysiology, 98(2), 310-320. 
[25]. Silvia, P. J., Beaty, R. E., Nusbaum, E. C., Eddington, K. M., \& Kwapil, T. R. (2014). Creative motivation: Creative achievement predicts cardiac autonomic markers of effort during divergent thinking. Biological Psychology, 102, 30-37. doi: 10.1016/j.biopsycho.2014.07.010

[26]. Dunkel, C. S. (2015). In France, are secular IQ losses biologically caused? A comment on Dutton and Lynn (2015). Intelligence, (53), 81-85.

[27]. Sternberg, R. J. (2015). Successful intelligence: A model for testing intelligence beyond IQ tests. European Journal of Education and Psychology, 8(2), 76-84. https://doi.org/10.1016/j.ejeps.2015.09.004
[28]. Van der Fels, I. M., Te Wierike, S. C., Hartman, E., Elferink-Gemser, M. T., Smith, J., \& Visscher, C. (2015). The relationship between motor skills and cognitive skills in 4-16 year old typically developing children: A systematic review. Journal of science and medicine in sport, 18(6), 697-703. doi: 10.1016/j.jsams.2014.09.007.

[29]. Schmidt, M., Jäger, K., Egger, F., Roebers, C. M., \& Conzelmann, A. (2015). Cognitively engaging chronic physical activity, but not aerobic exercise, affects executive functions in primary school children: a group-randomized controlled trial. Journal of Sport and Exercise Psychology, 37(6), 575-591. doi: 10.1123/jsep.2015-0069.

[30]. Sviderskaya, N. E., \& Antonov, A. G. (2008). Influence of individual psychological features on the EEG spatial organization in nonverbal divergent thinking. Human Physiology, 34(5), 565-573. https://doi.org/10.1134/S0362119708050046 